EstAg 29 (1994) 429-453

\title{
La enseñanza escolar en el antiguo Israel
}

Es muy probable que fuera Voltaire el primero que negó la existencia de la enseñanza escolar en el A. T., aduciendo una razón a primera vista no desdeñable. Escribía en el Diccionario Filosófico: "Lejos de tener escuelas para instrucción pública de la juventud, su lengua (la de los judíos) careció incluso de un término que designara esta institución ${ }^{1}$.

Efectivamente el hebreo carece de un término que signifique escuela. Solamente el tardío libro del Sirácida la menciona con el nombre de "Bet Midrash"= "Casa de la enseñanza" (Sir 51,23). Pero estamos en el s. II, nada menos que 800 años después de David y Salomón, con lo que el testimonio no se puede aducir para probar la existencia de las escuelas en el antiguo Israel.

Pero evidentemente no son los filósofos los que tienen que discutir este tema, sino los escrituristas. Y ciertamente lo han hecho en el pasado y en el presente.

Desgraciadamente no hay nada escrito en castellano sobre la escuela en el Antiguo Israel. Por esta razón nos proponemos en estas páginas informar detenidamente aduciendo los argumentos a favor y en contra, clarificando el tema en la medida de lo posible.

Hace ya algunos años J. A. G.-Larraya publicaba sobre la educación un artículo en la Enciclopedia de la Biblia que puede servir de punto de partida. Afirmaba lo siguiente: "En el A. T. no consta de modo explícito que hubiera escuelas en la acepción ordinaria del vocablo. No aparecen documentalmente como tales hasta el periodo helenístico. Sin embargo, debieron existir lugares de educación distintos de la casa familiar, en los que hombres enseñarían a muchachos oficios y artes ${ }^{2}$.

Dos puntos deben tenerse en cuenta en este párrafo: la afirmación rotunda de la ausencia de documentación, y de otra parte la suposición de que debieron existir lugares de educación. A éstos, distintos de la casa familiar, no se atreve a llamarlos escuelas. Se adivina en el párrafo cierta perple-

1. Oeuvres Complètes, T. XXXVII: Dictionnaire Philosophique. T. V. Paris, 1819, 40, bajo la voz "Judíos".

2. Enciclopedia de la Biblia. Barcelona, 1963, T. II, cols. 1071-1081. La cita en la col. 1073. 
jidad; ésta es la sensación que tiene quien estudia con cierto detenimiento el tema. Y es que en realidad se sabe poco de la enseñanza en el Israel antiguo.

Aunque hay quienes niegan hoy la existencia de la enseñanza escolar, al menos, durante la monarquía, es, sin embargo, más común defender la existencia de la misma, si bien, a veces, no está claro si la afirmación se refiere también a la época anterior al destierro.

Se suele citar a A. KLOSTERMAN ${ }^{3}$ como el primero que reunió los argumentos a favor de la existencia de las escuelas e influyó decisivamente en los autores siguientes ${ }^{4}$.

Merece también citarse a L. Dürr ${ }^{5}$, quien, habiendo reunido la información sobre el sistema escolar en Egipto y Mesopotamia, se mostraba favorable por analogía a la existencia de escuelas en Israel. He aquí enunciado un argumento que se citará frecuentemente.

Es muy común que los autores especialistas o dedicados preferentemente a los libros sapienciales se muestren favorables a la existencia de las escuelas. Así G. von $\operatorname{Rad}^{6}$, J. Hermisson ${ }^{7}$, O. Loretz ${ }^{8}$, W. McKane ${ }^{9}$.

Actualmente los autores más combativos a favor son B. Lang y A. Lemaire. Ambos han vuelto repetidamente sobre el tema.

El primero, sin desdeñar otros argumentos, se apoya principalmente en los libros sapienciales. Cree encontrar el "Sitz im Leben" del libro de los Proverbios, especialmente de Prov 1-9, en las escuelas. Serían trozos antológicos o florilegios usados en la escuela para aprender a leer y a escribir ${ }^{10}$. $\mathrm{Al}$ segundo se le debe la única monografía sobre el tema y argumenta más a partir de la arqueología y epigrafía ${ }^{11}$.

La posición contraria a la enseñanza escolar fue mantenida en tiempos pasados por L. Köhler ${ }^{12}$ y por E. Mangenot ${ }^{13}$.

3. "Schulwesen im Alten Israel": Fs. Theodor Zahn. Leipzig 1908, 193-232.

4. B. LANG, "Schule und Unterricht im Alten Israel": M. GILBERT (ed.), La Sagêsse de l'Ancien Testament. Gembloux-Leuven 1979, 186.

5. Das Erzhiehungswesen im alten Testament und im antiken Orient. Leipizg 1932.

6. La Sabiduría en Israel. Los Sapienciales. Lo Sapiencial. Madrid 1973, 34.

7. Studien zur israelitichen Spruchweisheit. (WMANT 38). Neukirchen-Vluyn 1968, 97-1136.

8. Qohelet. Freiburg 1964,91-94.

9. Prophets and Wise Men. London 1965, 36ss.

10. B. LANG, Die weisheitliche Reden. Stuttgart 1972, 193-232; ID. Frau Weisheit. Deutung einer biblischen Gestal. Düsseldorf 1975; ID, Schule, 186-201; ID. Wie wird man Prophet in Israel. Düsseldorf 1980, 31-58.

11. A. LEMAIRE, Les Ecoles et la formation de la Bible dan l'Ancien Testament. FribourgGöttingen 1981. Citaremos la versión italiana, Le Scuole e la formazione della Bibbia nell'Israele antico. (Studi Biblici 57). Brescia 1981; ID. "Abécedaires et éxercices d'écolier en épigraphie norwest sémitique": Journal Asiatique (1978) 221-235; ID. "Sagêsse et Ecoles": Vetus Testamentum 34(1984)270-281.

12. Der Hebräische Mensch. Tübingen 1953, 46.

13. Dictionnaire de la Bible: "Education", II, cols. 1595-6: "Chez les Hébreux l'education des enfants se faisait exclusivement dans la famille et était sur tout l'oeuvre des parents" (col. 1595). 
Actualmente sigue manteniendo una posición contraria y muy escéptica R. N. Whibray ${ }^{14}$. Se ha significado especialmente F. Golka como absolutamente contrario a las escuelas ${ }^{15}$.

\section{Qué se entiende por enseñanza escolar}

Los autores que tratan el tema no suelen dedicar atención alguna a la definición de la escuela y a cuáles son los elementos de esta institución. Sin embargo, es absolutamente necesario saber qué se entiende por escuela si queremos examinar si esta institución existió en Israel. Solamente J. Crenshaw ${ }^{16}$ enumera las condiciones que, según él, son necesarias para que se pueda hablar de enseñanza escolar: 1) Maestros o profesores pagados, es decir, profesionales, 2) enseñanza de la lectura y escritura, 3) enseñanza dada en lugar distinto de la casa paterna. Estas exigencias a primera vista son razonables. Consiguen distinguir la enseñanza escolar de la familiar.

En Roma, por ejemplo, en la época antigua se enseñó a leer y a escribir en la familia, sistema defendido acérrimamente por el célebre Catón. Las referencias a las escuelas sólo son frecuentes a partir del s. III a. C. ${ }^{17}$.

Sin embargo, la definición de Crenshaw no es apta para distinguir la enseñanza escolar del conocido sistema llamado del "famulus" o aprendiz, debido a que solamente incluye en el "curriculum" la alfabetización. El "famulus" aprende mirando y copiando, hasta conseguir la destreza del maestro. Según Brunner, éste fue el método usual en Egipto en la época del Imperio Antiguo ${ }^{18}$.

Quizá deba verse una alusión bíblica a este método de enseñanza en 1 Sam 1-3. Samuel es llevado junto al sacerdote Elí para que aprenda el oficio al mismo tiempo que los propios hijos del sacerdote.

Dado que en realidad se ha dado este otro tipo de enseñanza, se han de evitar conclusiones apresuradas en este campo. G. von $\operatorname{Rad}^{19}$ afirmaba que "la escritura no ha sido enseñada jamás sin una doctrina relativa a ella. De donde se deduce que tuvieron que existir en Israel escuelas de diversas cla-

14. The Intelectual Tradition in the Old Testament (BZAW 135). Berlin 1974, 33-43; ID. "Yahweh-Sayings and their Context in Proverbs 10,1-22,16": M. GILBERT (ed.). La Sagêsse de l'Ancien Testament. Gembloux-Leuven 1979, 135-136: "The Existence of Schools in Israel in pre-hellenistic times is itself doubtful" (p. 155, nota 8); ID. "Wisdom Literature in the Reigns of David and Salomon": T. ISHIDA, (ed.) Studies in the Period od David and Salomon. Tokio 1982, 13-26.

15. "Die israelitische Weisheitschule oder der'Kaisers neue Kleider"': Vetus Testamentum 33(1983) 257-270.

16. "Education in Israel": Journal of Biblical Literature 104(1985) 602.

17. J. BOWEN, Historia de la educación occidental. Barcelona 1976, T. I. 238-243.

18. H. BRUNNER, Altägyptische Erziehung. Wiesbaden 1957, 10ss..

19. La Sabiduria, 34. 
ses". Parece deducir de la existencia de la escritura a la existencia de escuelas. Lo que evidentemente es una conclusión falsa.

Por otra parte, la capacidad de leer y escribir no es un concepto bien definido. La tienen los escribas profesionales capacitados por una larga preparación para componer incluso obras literarias. Al otro extremo un alfarero, por ejemplo, puede ser suficientemente hábil para saber grabar en una vasija unas cuantas letras e incluso palabras. Afirmar que éste sabe leer y escribir es puramente convencional. Y seguro que el tal alfarero no necesitó ir a una escuela.

Se impone, pues, distinguir dos tipos de escuelas. Unas de alta capacitación para escribas profesionales y otras de más bajo nivel cultural llamadas a cubrir las necesidades básicas de lectura y escritura. A. Lemaire distingue estas dos clases de escuelas y, según él, hubo un desarrollo progresivo: de las escuelas para escribas profesionales en la época de David y Salomón se pasó en el s. VIII a una generalización amplia. Hubo escuelas no sólo en los grandes centros y fortalezas sino también en la mayor parte de las aldeas ${ }^{20}$.

Estas dos afirmaciones, la existencia de las escuelas para escribas profesionales desde la época de David y Salomón y las escuelas para la alfabetización general, son las que están sujetas a debate, y que necesitan probarse.

\section{La analogía con las culturas del Próximo Oriente}

Este argumento es muy frecuentemente citado por los partidarios de la existencia de escuelas en Israel. Si Egipto y Mesopotamia ya disponían de escuelas cuando Israel como nación comenzó a existir, es normal pensar que esta institución también se instalara en Palestina. Este argumento parece fuerte si se tiene en cuenta que Egipto ejerció gran influencia en Palestina durante la segunda mitad del segundo milenio, es decir, durante el Imperio Nuevo.

Hay que advertir que la comparación se establece siempre con Egipto y Mesopotamia. Ahora bien, estos dos imperios tenían una civilización muy superior en todos los campos a la de Israel. Sería más interesante y apropiado establecer la comparación con Moab, Ammón y Edón, por ejemplo, que son estados que surgieron casi al mismo tiempo que Israel y supuestamente disponían de un parecido nivel cultural. Pero, por desgracia, estas naciones limítrofes con Israel han dejado escasos restos culturales.

Por otra parte, se compara Israel que dispuso desde el principio de escritura alfabética con Egipto y Mesopotamia, que gozaban de una escritura totalmente diferente. Debido a ello el escriba tuvo un papel tan relevante en la cultura egipcia: necesitaba muchos años de estudio para el aprendizaje de 
los jeroglíficos y signos gráficos, mientras que en Israel la escritura alfabética facilitaba enormemente la democratización del aprendizaje.

De todas formas, en cuanto a Egipto, consta que durante el Imperio Medio (c.2050-1800) las escuelas de escribas funcionaban ya perfectamente organizadas con sus maestros, sus libros de texto, sus métodos pedagógicos, etc. El escriba tenía un prestigio grande. Era una profesión ansiada por todos. Ser admitido en la escuela era ya un privilegio, pues la competencia era mucha. La educación era evidentemente elitista y los escribas guardaban con cuidado para sí el conocimiento de la escritura.

La impresión que el profano saca al leer a los especialistas del tema es que la capacidad de leer y escribir debía estar muy generalizada. Tal es la conclusión que cabe extraer de esta frase del conocido egiptólogo H. Brunner: "Cualquier egipcio podía llevar a su hijo a la escuela durante el Imperio Medio" 21.

Personalmente pienso que esta frase es una exageración. La frase supone una movilidad social de tal calibre que muchísimos estados modernos no han alcanzado hasta épocas muy recientes. Durante el Imperio Antiguo y Medio "la sociedad egipcia se hallaba dividida en tres clases: hombres cultos que ejercían una autoridad derivada del Faraón, aquéllos que les estaban subordinados (guardianes de las puertas, soldados, canteros, etc.) y el campesinado analfabeto ${ }^{22}$. Para una época más reciente el papiro Wilbour (ca.1143) nos proporciona una descripción de un sector típico de la sociedad: un grupo reducido de funcionarios ricos y de alto rango y un grupo mucho más numeroso de burócratas, sacerdotes, soldados, mozos de cuadra, agricultores y pastores. Particularmente los agricultores sobre los que pesaba la economía egipcia, los más numerosos sin duda, vivían en un estado bien precario, y para ello basta leer la sátira de los oficios ${ }^{23}$. Pensar que estos campesinos podían mandar a sus hijos a la escuela es una quimera.

Se encuentran muy documentadas las escuelas en Egipto para los escribas, adscritas al palacio y a los templos, pero no consta la escuela pensada para la alfabetización generalizada. En el primer tipo de escuelas el alumno debía ejercitarse por largo tiempo en el aprendizaje de la escritura, tarea ímproba, que requería largo periodo de instrucción y de ejercicio. Para ello disponían de florilegios y antologías, verdaderos libros de texto, que proporcionaban, además, otra clase de conocimientos, como la Geografía e Historia, las Ciencias Naturales, sin descuidar la formación propia y el modo de

21. "In die Schule des Mittleren Reiches dagegen konnte wohl jeder Aegypter sein Kind bringen..." H. BRUNNER, Altägyptische, 43.

22. B. G. TRIGGER (y otros) Historia del Antiguo Egipto. Barcelona 1985, 110.

23. Puede verse una versión española de este escrito egipcio en J. M. PEREZ SERRANO, Textos para la historia antigua de Egipto. Madrid, 1993, 221-225; una descripción dramática de las profesiones más humildes del Antiguo Egipto puede leerse en S. DONADONI, El hombre Egipcio. Madrid 1991. 
relacionarse con los demás que le serían de provecho en su su vida profesional posterior. Naturalmente los maestros les infundían a los alumnos un alto aprecio de su profesión, pues "no hay escriba que carezca de comida y de bienes de palacio" 24 .

Periodo tan largo y tan costoso (la enseñanza había que pagarla) de instrucción era un lujo que no estaba al alcance de la inmensa mayoría de la población.

Además de las escuelas para escribas, existían otras menos numerosas llamadas "escuelas de la vida", pero éstas proporcionaban una enseñanza superior referentes a temas religiosos y científicos.

Por tanto, nada de escuelas disponibles para todos. Y es que en la antiguedad, "cualquiera que fuere la sociedad considerada, la escuela se concibió para una minoría" 25 .

La misma situación más o menos se refleja en Mesopotamia. También la escuela procede directamente de la escritura, en concreto de la escritura cuneiforme inventada por los sumerios. Las tablillas más antiguas son de comienzos del III Milenio. De la segunda mitad del citado milenio proceden muchas tablillas que son verdaderos ejercicios escolares, obra de los alumnos. También aquí como en Egipto la enseñanza consistía al principio en el aprendizaje de la lectura y escritura.

La enseñanza tampoco era ni general ni obligatoria ${ }^{26}$. Esto no es una suposición, sino un dato atestiguado por los textos. En tablillas correspondientes al año 2.000 a. C. se hallan mencionados unos 500 escribas, que anotan además del nombre propio el nombre del padre y la profesión. Pues bien, todos lo padres de los alumnos son gobernadores, embajadores, administradores de los templos, altos funcionarios, etc. Ninguno procede de la clase baja.

A favor del carácter restringido del saber leer y escribir debe citarse lo que Assurbanipal, emperador de Asiria, dejó grabado en un prisma de barro de diez caras. En la introducción dice de sí mísmo: "Yo, Asurbanipal, en el palacio comprendí la sabiduría de Nebo, todas las artes de la escritura y de toda artesanía, de todas las clases las he dominado... Comprendo las inscripciones en piedra de antes del Diluvio que son herméticas, vagas y complicadas...". Como sabemos que fue un príncipe apasionado por la cultura, estas palabras no tendrían nada de particular si no leyéramos una tablilla de su biblioteca de Nínive en donde dice: "entre los reyes que ha habido antes, ninguno supo este arte..." ${ }^{27}$. Es posible que haya un poco de jactancia en estas palabras. Revelan, desde luego, el empeño del emperador por apren-

24. Sátira de los oficios, en J. M. SERRANO DELGADO, ob. cit. 224.

25. V. ISAMBERT JANATI, s.v. Education: Encyclopedia Universalis. Corpus. 6, 649.

26. S. N. KRAMER, La historia empieza en Sumer. Barcelona 1985,40.

27. A. A. MOORHOUSE, Historia del alfabeto. México 1961, 258; E. CASSIN-J. BOTTERO-J. VERCOUTTER (eds.), Historia universal siglo veintiuno. vol. 4. Los imperios del antiguo Oriente. III. La primera mitad del primer milenio. 3 ed. México 1973, 78-79. 
der y por la cultura, como lo demuestra el hecho de que dejara una biblioteca de 25.000 tablillas, en las que no solo hay anales, cartas, contratos, documentos administrativos o económicos, sino también poemas, epopeyas, mitos, fábulas, sabidurías, etc. Pero queda en pie la afirmación de que los emperadores anteriores no sabían leer ni escribir. Y este emperador es de un periodo relativamente reciente. Muere en 632 a. C.

Impone también cierta prudencia el hecho de que la escritura surge por necesidades prácticas, en realidad por intereses comerciales.

"La necesidad de llevar una contabilidad, junto con el deseo de registrar las hazañas reales, parece haber sido la causa fundamental del desarrollo de la escritura en Egipto" 28.

La escritura era una técnica y los contemporáneos la consideraban como tal. El 90 por ciento de los textos sumerios son documentos de administración, de tal manera que la escritura era un medio de la misma. La e.du.ba o casa de las tablillas, es decir, la escuela preparaba escribas, a los que se les pagaba como obreros especializados ${ }^{29}$.

En todo caso, queda en pie la existencia de escuelas para escribas tanto en Mesopotamia como en Egipto. Este dato ha sido determinante para la extrapolación de las escuelas a Israel. Es, quizá, el argumento más repetido por los favorables a la hipótesis escolar. Se piensa que David y Salomón al organizar el reino necesitarían también sus empleados y funcionarios, concretamente escribas. De hecho tenemos dos listas de los funcionarios de David que apenas difieren ente sí: 2 Sam 8,16-18 y 2 Sam 20,23-25. En estas listas aparecen dos funcionarios: uno llamado sofer = escriba y otro llamado mazkir, que se suele traducir por heraldo. Desde J. Begrich ${ }^{30}$ es común ver un paralelismo entre estos cargos y dos altos funcionarios de egipcios en la corte del faraón.

El argumento de analogía encuentra objeciones graves. Unas provienen de la historia, otras, de la sociología.

La fiabilidad de los datos históricos de la Biblia referentes al periodo histórico de que tratamos es cuestionable. La imagen que la Biblia nos presenta del reino de David y Salomón, ¿responde a la realidad? En la década de los cincuenta, la Historia de Israel de M. Noth escandalizó a no pocos, porque consideró como prehistoria todo lo anterior a la época de los Jueces. Según él, la historia empieza con la liga de las doce tribus en Palestina. Las etapas anteriores son oscuras y opacas. En estos últimos años el límite entre la prehistoria y la historia ha sufrido otro desplazamiento. Sin llegar al extremo de G. Garbini ${ }^{31}$ que considera la narración del imperio davidico-salomó-

28. B. G. TRIGGER (y otros), Historia, 83.

29. D. ARNAUD, Le Proche-Orient Ancien: de l'invention de l'écriture à l'hellénisation. Paris 1970, 13.

30. "Sofer und Mazkir": Zeits. f. d. Alttestam. Wissens. 58 (1940-1941)1-29.

31. Storia e Ideologia nell'Israele antico. Brescia 1986. 
nico como un producto de fantasías, en parte proyección hacia atrás del reinado de un Azarías (rey, según él, de Samaría), lo cierto es que las últimas "Historias de Israel" ponen la línea divisoria entre la historia y la prehistoria o protohistoria en el reinado de David. Así, por ejemplo, J. A. Soggin ${ }^{32}, \mathrm{H}$. Donner ${ }^{33}$, J. Maxwell Miller-J. J. Hayes ${ }^{34}$. Este comienzo de la historia con David no significa que estos autores den por buenas las tradiciones que se nos transmiten de esta época. Las razones de esta desconfianza son sencillas: las fuentes de que disponemos son redaccionalmente tardías. Y muchas narraciones están escritas "ad maioren gloriam" de los dos reyes.

Es verdad que la Historia de la sucesión al trono de David (2 Sam 9-20+1 Re 1-2) goza todavía de prestigio histórico porque se la cree, o mejor, se la creía escrita por un autor cercano a los hechos. Sin embargo, el lector tiene que leer escenas de alcoba y oir lo que los protagonistas dicen en tales lugares. Esto no es propio de un historiador sino de un contador de historias. Definirla como una "novela histórica" ${ }^{35}$ no debe extrañar. Por otra parte, modernamente se reconoce que el Dtr ha intervenido en su redacción y, además, la semejanza entre las guerras de David y las de Saul son tales que se desconfía de su valor histórico ${ }^{36}$.

De otra parte, no se conserva testimonio alguno del imperio de David en los textos extrabíblicos. Aunque este es un argumento de silencio, no deja de sorprender. De este modo la reconstrucción de los sucesos reposa totalmente sobre los textos bíblicos, llenos de tendencias teológicas e ideológicas clarísimas. Los datos bíblicos no son controlables por fuente alguna fuera de la misma Biblia.

Por lo que se refiere a nuestro tema, es interesante observar aquí, que el texto de 1 Re 5,1.4 que describe los límites del imperio de Salomón como si abarcara "desde el río (Eufrates) hasta el límite con Egipto" contiene evidentemente una exageración. Está en contradicción, al menos, con $1 \mathrm{Re}$ 11,23-25 que habla de la independencia de Damasco, cuyo rey "fue adversario de Israel toda la vida de Salomón". Por lo demás, el carácter tardío de este texto ha sido reconocido desde antiguo ${ }^{37}$.

Ahora bien, si hay que redimensionar el llamado ampulosamente "imperio de David y Salomón", entonces los altos funcionarios de David a que nos hemos referido, no deben imaginarse como personajes al frente de un minis-

32. Storia d'Israele. Brescia 1984.

33. Geschichte des Volkes Israel und seiner Nachbarn in Grundzügen. Göttingen 1984.

34. A History of Ancient Israel and Judah. London 1986.

35. R. N. WHIBRAY,The Succession Narrative. London-Philadelphia 1968.

36. R. C. BAILEY, David in Love and War.The Pursuit of Power in 2 Samuel 10-12. Sheffield 1990,130 .

37. J. A. MONTGOMERY - H. S. GEHMAN, The Books of Kings (International Critical Commentary). Edinburgh 1951,126-129; E. WÜRTHWEIN considera estos versículos como adiciones postdeuteronomistas. (Die Bücher der Könige) (ATD 11). Göttingen 1985, I, 43.47. 
terio al estilo de los estados más desarrollados. Todo debió ser mucho más modesto. Saul al parecer no tenía corte. En una generación no se monta un estado con su administración.

De este modo tiene sentido la siguiente pregunta: ¿es preciso imaginarse escuelas en la corte y en los templos para preparar a los funcionarios y todo ello en una época tan temprana? O, más bien, ¿hay que pensar en un tipo de enseñanza al estilo del "famulus" o aprendiz? Siendo la escritura alfabética como es el caso de Israel, su aprendizaje es relativamente sencillo ${ }^{38}$.

Así piensan R. N. Whibray ${ }^{39}$ y P. Nel ${ }^{40}$. Un indicio a favor de esta opinión cree encontrar Golka en el hecho siguiente: Elijorep y Ajías (1 Re 4,3), los escribas de Salomón, son hijos de Sisa, que era el escriba de David. Al parecer el oficio era hereditario. Este sistema vuelve a aparecer con la familia de Safán. Este era secretario del rey Josías ( 2 Re 22), y luego del rey Joaquím. Sus hijos Ahikam (Jer 26,24) y Guemarías (Jer 36,10) lo son luego del mismo rey, y el nieto Miqueas al parecer continúa con la profesión de sus mayores (Jer 36,11-13).

También la sociología tiene algo que decir en este trasvase fácil que se hace de instituciones de un país a otro. En todas y cada una de las actividades sociales, económicas y políticas Egipto y Mesopotamia no admiten comparación con Israel. Cantidad de población, extensión de las ciudades, edificios y obras públicas, administración, comercio, obras de arte, especialización del trabajo, etc., todos son datos tan dispares que es preciso ser cauto al extraer conclusiones, sobre todo si se tiene en cuenta que la escritura era una técnica que se pagaba. Por tanto será preciso demostrar antes que la sociedad necesita esos técnicos. Se ha dicho con razón que las instituciones no son exportables como las joyas de una familia ${ }^{41}$. Volveremos sobre este punto.

38. W. F. Allbright llegó a afirmar que el alfabeto de 22 letras podía ser aprendido por un alumno inteligente en un par de días y por el alumno más torpe en un par de semanas. Para tal espacio de tiempo evidentemente no hace falta escuelas. B. Lang le reprocha no haber dado clase a niños pequeñitos, de lo contrario llegaría a la conclusión de que un par de años son necesarios. (Schule und Unterricht... p.190-191). Es una discusión sin sentido, pues entra una variable importante: la edad del alumno. B. Lang habla de un niño, mientras que Allbright esta pensando en un adolescente o adulto. La cuestión es otra muy distinta. Si el reino necesitaba empleados y escribas, el oficio de estos requería algo más que saber leer y escribir, por ejemplo contar, hacer ciertos cálculos, fórmulas jurídicas y testamentarias, etc.

39. The Intelectual Tradition... 38.

40. "The Concept of Father in the Wisdom Literature of th Ancient Near East": Journal of the Ancient Near Eastern Society 5 (1977) 60s.

41. J. B. PRICE, "Secondary State Formation: An Explanatory Model" : R. COHEN-E. R. SERVICE, Origins of the State, citado por D.E. JAMIESON-DRAKE, Scribes and Schools in Monarchic Judah. A socio-Archeological Approach. Sheffield 1991, 23. 
En todo caso cabe decir que el argumento de la analogía no consigue probar la existencia de las escuelas en Israel, pues permanece exterior al tema que nos ocupa.

\section{Los textos bíblicos}

Los favorables a la existencia de escuelas buscan textos bíblicos en los que fundar este tipo de enseñanza. Y esto se ha hecho desde Klostermann.

Todavía A. Lemaire ${ }^{42}$, siguiendo a L. Dürr y a H. J. Hermisson cita numerosos textos; él mismo reconoce que muchos de ellos no sirven; es sintomático que el título del capítulo en que recoge los textos bíblicos sobre la escuela esté expresado en interrogativo: ¿Alusión a la existencia de escuelas en la Biblia? No es difícil imaginar por qué.

Citar, como se ha hecho, los casos de Samuel junto a Elí (1 Sam 1-3) o Salomón junto a Natán (2 Sam 12, 24-25) o la instrucción del rey Joás junto al Sacerdote Yoyadá ( $2 \operatorname{Re} 12,3)$, como ejemplos de enseñanza escolar está fuera del lugar. Para expresarnos vulgarmente, es como citar la soga en casa de un ahorcado. Si algo dicen estos textos, es que había un tipo de enseñanza distinto de la escolar.

Tampoco el texto de Isaías 8, 16-17 aporta nada de particular. Al final de una época de predicación (se piensa que estos versículos cerraban primitivamente las Memorias de Isaías) este texto hace una especie de balance. Su mensaje no ha sido aceptado ni por el pueblo ni por el rey. Sin embargo, el testimonio del profeta no ha de perderse, sino conservarse, con el fin de que la generación futura sepa que la catástrofe que va a venir había sido ya anunciada.

"Quiero encordelar mi testimonio, sellar mi enseñanza en mis discípulos" ${ }^{43}$.

De dos maneras puede interpretarse el texto: literalmente él hablaría del testimonio escrito de su predicación que el profeta confía a sus discípulos para que lo guarden y conserven. En este caso el texto hablaría de una especie de acto jurídico. O bien puede entenderse en sentido metafórico. Los discípulos son los que deben conservar y transmitir el testimonio de generación en generación sin alusión alguna a la escritura de un documento.

Para nuestro tema nada contiene el texto de importante. El término lmdy designa aquí los discípulos del profeta. Sería alusión a algunos seguidores que Isaías tuvo. El predicaba públicamente y es normal pensar que algu-

42. Le scuole... 38ss.

43. Con los nuevos comentaristas entendemos los verbos como imperativos absolutos y no como infinitivos. Vease H. WILDBERGER, Jesaja. Neukirchen 1972, I, 342; O. KAISER, Das Buch der Propheten Jesaja. Göttingen 1981, I, 188. 
nos le escuchaban con agrado y le apoyaban. A éstos se refiere el texto. Está fuera de lugar ver aquí una alusión a la enseñanza escolar.

Otro texto suele citarse aunque todos reconocen que es muy oscuro. Nos referimos a Isa 28,7-13. Generalmente se le considera como perteneciente a Isaías a excepción de los versículos 7 a y 13 . El primero es, sin duda, redaccional, pues pretende unir este oráculo con el precedente, en el que se habla también de borrachos, pero el escenario y los personajes a quienes se dirige son diferentes. Los dos textos quedan así unidos por medio de las palabrasenlace $s k r=$ licor y $y y n=$ vino. También el v. 13 es dudoso. Es verdad que después de la acusación del final del v. 12 ("no han querido escuchar") se esperaría una amenaza. Pero en este caso ya ha sido pronunciada en el v. 11, y además, y esto se ha advertido muchas veces, $13 b$ ha sido tomado al pie de la letra de 8,15 .

7. "También éstos se tambalean por el vino

y el licor les hace dar traspiés

Sacerdotes y profetas se tambalean por el licor,

se atontan con el vino,

el licor les hace dar traspiés,

se tambalean con sus visiones,

titubean en sus decisiones.

8. Pues todas las mesas están llenas de vómitos repugnantes y no hay sitio libre.

¿A quién quiere enseñar?

9. ¿A quién quiere exponer la revelación?, ¿a recién destetados?, ¿a los que acaban de dejar el pecho?

10. Pues (dice):

saw lasaw saw lasaw

qaw laqaw, qaw laqaw

zeer sam, zeer sam.

11. Verdaderamente y en lengua extraña

hablará a este pueblo

12. El, que les había dicho:

"éste es el lugar de reposo,

dejar que descansen los fatigados.

Este es el lugar de reposo".

Pero no quisieron escuchar.

13. Ahora el Señor les dirá:

"saw lasaw sau lasau

qaw laqaw qaw laqaw

zeer sam, zeer sam".

Los vv. 7-8 contienen un reproche de Isaías contra los sacerdotes y profetas. El mismo Isaías pudo haber presenciado la escena: Sacerdotes y Profe- 
tas durante las comidas sacrificiales en el templo se emborrachan y en este estado desatinan los sacerdotes al dar sus sentencias y los profetas desvarían al exponer sus visiones. La glotonería es tal que las mesas están llenas de vómitos.

Ante esta grave acusación, los atacados responden soberbiamente a Isaías. Pero ¿quién es Isaías para instruirnos a nosotros que tenemos el conocimiento (del derecho divino) y la interpretación de la revelación. ¿Somos acaso recién destetados e ignorantes bebés? A continuación se burlan de Isaías con esas expresiones misteriosas que dejamos sin traducir.

A veces se han entendido así: $s a u$ (sw) se pone en relación con la raíz $s w$, y se traduce algo así como mandato, y qaw (qw) se pone en relación con $q w^{\prime}$ y se traduce por esperanza. Luego $z$ 'r sm se traduce un "poco (un rato) aquí", "un poco allá", es decir, los profetas y sacerdotes se burlarían del mensaje de Isaías que unas veces predica amenazas y otras pronuncia palabras de esperanza. Con ello los adversarios de Isaías expresarían algo así como que Isaías siempre está reprochando o aplaudiendo, y uno no sabe a qué atenerse con él ${ }^{44}$. La dificultad de esta interpretación está en que los términos $s w$ y $q w$ no ocurren nunca con el significado de "mandato" y "esperanza" respectivamente. Por otra parte no se entiende a qué se debe que los sacerdotes y profetas se quejen de ser tratados como niños por Isaías.

Otra interpretación posible es entender $s w$ como una abreviación de miswa ="orden" o también como una derivación de un supuesto término sawa ="regla"; y qw con el significado de "cinta de medir". En este caso los adversarios de Isaías le reprocharían que el profeta esté continuamente moralizando. La dificultad en este caso reside en que no se halla atestiguado el significado metafórico de $q w$ y que no consta que $s w$ pueda ser una abreviación de miswa ni tampoco un derivación del substantivo sawa.

Otros renuncian a entender estas palabras misteriosas. Sencillamente los sacerdotes y profetas se burlarían de Isaías que debía tener algún defecto en su pronunciación. Evidentemente esto es una mera suposición sin garantía alguna.

Hay también algunos que creen encontrar una alusión a la enseñanza escolar. Notando que los adversarios de Isaías se quejan de que se les trate como niños, el v. 10 expresaría el modo que usa el maestro para enseñar a los niños. El profesor, acomodándose, usaría el vulgarismo de llamar saw a la letra sade y qaw a la letra qof. Igualmente entienden $z$ 'r no en sentido neutro, sino masculino, de tal manera que traducen así "pequeño aquí, pequeño allá", como si el maestro estuviera reconviniendo a los niños. Para que no falte nada al cuadro G. R. DRIVER propuso leer sym en vez de sm; de este modo podría traducirse, "niño, atención". 
Ultimamente A. von SELMS ${ }^{45}$ ha propuesto una nueva interpretación que ha tenido poco eco. Entiende los vv. 9-13 independientemente de los vv. 7-8. No hay diálogo ninguno. Quien habla es el profeta. El sujeto es siempre Dios. En el v. 9 hay una especie de "reductio ad absurdum". El sentido es el siguiente: ¿Acaso Dios va a comunicar su revelación y sus visiones a los recién destetados? ¿Por qué iba a hacer Dios esto? La respuesta es la siguiente: Porque Dios va a hablar en lengua extranjera a su pueblo. Apoyándose en este versículo, entiende los términos misteriosos como una transcripción del asirio que traducido diría lo siguiente: "Sal, que salga, espera, que espere. Esclavo, escucha". Esta sería la amenaza que Isaías pronuncia.

Esta interpretación lleva consigo corregir el texto hebreo: leer sy y no $s w$ (como en 1 QIsa) y qy y no $q w$.

La interpretación del v. 9 es un tanto alambicada. No se ve a qué obedece la mención de los niños recién destetados, si su modo de hablar no es imitado. Por otra parte habría que suponer en Isaías, en los oyentes y en lo transmisores un conocimiento del asirio bastante profundo.

En resumen, varias son las interpretaciones que se dan del texto. Sólo según una de ellas contendría una alusión a la enseñanza escolar. Interpretación esta que no deja de tener sus dificultades. Por ejemplo, no explica por qué se dice laqaw y no simplemente qaw, como sucede con el sade.

Además, aunque se imite el modo de enseñar, no necesariamente se refiere a las escuelas. Es evidente que en tiempo de Isaías se enseñaba la lectura y escritura. Estas cosas se han enseñado muchas veces sin escuelas. Por tanto el texto tampoco debe tomarse como una alusión a la enseñanza escolar.

A veces se cita tambien a Isa 50,4. Forma parte del tercer poema del Siervo de Yahve que se expresa así:

\section{"El Señor me ha dado lengua ejercitada para que haga saber al cansado una palabra alentadora, cada mañana despierta mi oído, para escuchar como los discípulos".}

Se discute el significado de $l m d m$ que recurre dos veces en este párrafo. La primera vez puede traducirse en foma adjetivada, como hemos hecho, dado que el término está en plural y hace mejor sentido ${ }^{46}$. La segunda vez es evidentemente un sustantivo. El siervo se compara con los discípulos y como ellos escucha atentamente a su maestro, que evidentemnte en este caso es Dios. Es curioso que en el A. T no se hable nunca de la relación entre maes-

45. "Isaiah 28,9-13: an Attempt to give a New Interpretation": Zeits.f.d. Alt. Wissens 85(1973)332-339.

46. Así lo entienden los diccionarios de Gesenius-Buhl y Gesenius-Briggs. 
tro y discípulo o de profesor y alumno, sino siempre de los enseñados por Dios ${ }^{47}$.

La imagen, ¿supone la enseñanza escolar? Esto cabría concluir si en Israel no hubiera existido otra clase de discipulado más que el discipulado escolar. Y esto nadie se atreve a afirmarlo.

Tampoco tiene mayor importancia el tardío texto de 2 Cron 17, 7-9. Cuenta que Josafat, rey de Judá del s. IX, mandó a cinco empleados suyos, cuyos nombres da, a enseñar por las ciudades de Judá. Con ellos mandó a varios levitas, con el fin de enseñar la ley. Como el libro de los Reyes no dice absolutamente nada de esta misión, la noticia es difícil de evaluar. Por lo demás no aporta nada a la enseñanza escolar, pues en todo caso se trata de una misión extraordinaria.

$\mathrm{Y}$ estos son los textos más interesantes, claramente insuficientes para documentar cualquier clase de escuelas.

También se suelen citar textos bíblicos de los que se quiere deducir que la lectura y escritura estaban bastante extendidas. Así se cita al joven de Sukkot que es capaz de dar a Gedeón la lista de 77 hombres (Ju 8,14). Muy semejante es el texto de Isaías, según el cual "tan pocos árboles quedarán en el bosque que un niño los podrá contar" (Isa 10,19). El Deut prescribe que el marido al divorciarse debe escribir el libelo de repudio y dárselo a la esposa (Deut 24,1). Además el mismo libro obliga a todo israelita a escribir en los dinteles de la puerta las palabras de la ley (Deut 6,9;11,20). En Jer 32, 12 se citan testigos que pueden escribir su firma en una escritura de compra.

Estos textos valen poco. El joven de Sukkot no necesitaba saber mucho para dar la lista. El texto de Isaías lo que afirma es que no va a quedar ningun árbol o tan pocos que hasta un analfabeto los podrá contar. Los testigos que firman la escritura de Jeremías no necesariamente saben escribir. Por su parte, los textos del Deut no dicen que cada uno debía escribirlos; podían echar mano de un escriba. Hasta hace unos años no era raro encontrar en las centrales de correos o en oficinas estatales un escribano que rellenaba los impresos de la gente poco práctica o analfabeta por unas monedas.

\section{La enseñanza escolar y la sabiduría}

Los libros sapienciales, particularmente el más representativo de todos ellos, el libro de los Proverbios, persiguen una finalidad pedagógica. Quieren educar a la juventud a pensar y, sobre todo, a obrar bien. Intentan enseñar a quien les quiera escuchar, cómo se puede llegar a ser adultos responsables.

47. E. JENNI-C. WESTERMANN, Diccionario Teológico Manual del Antiguo Testamento. Madrid 1978,I, col.1195; K.H. RENGSTORF, THWNT, IV, 429. 
Este cometido es posible. El libro de los Proverbios está impregnado de un aire de confianza en las posibilidades del hombre. Confianza que surge de la observación de que la vida humana está regida por reglas que es menester primero descubrir y luego guardar.

Este afán pedagógico y educacional se asocia espontáneamente con maestros de sabiduría y éstos no son tales ordinariamente sin alumnos. Por ello es normal que se busque en los libros sapienciales pruebas y argumentos favorables a la enseñanza escolar.

Muchos interrogantes presenta la literatura sapiencial a la investigación bíblica. No es el menor de estos problemas explicar su origen. ¿Quiénes son los autores de los Proverbios? ¿En qué ambiente se cultivó la sabiduría? ¿Cuál es el lugar de donde procede esta reflexión racional sobre la experiencia?

Como las formas literarias del libro de los Proverbios son variadas, también su lugar de origen puede ser distinto.

4.1. En Prov 10-21 y 25-29 predominan los proverbios de dos hemistiquios (dos líneas, un solo verso). Contienen sentencias breves, coleccionadas, al menos aparentemente, sin criterio. Son observaciones sobre las más variadas circunstancias de la vida, en las que predominan las constataciones sobre los consejos.

¿Estos proverbios simples han brotado del saber popular oral o son obra de sabios maestros en la escuela?

La discusión es ya antigua y sigue viva. Citemos como favorables al origen exclusivamente escolar de los proverbios a G. von Rad, a su discípulo $\mathrm{H}$. J. Hermisson y a H. D. Preuss ${ }^{48}$.

La razón fundamental que aducen es la forma artística de los proverbios, que se nota entre otras cosas por el paralelismo de los miembros que, como es sabido, es la regla fundamental de la poesía hebrea. Además, abundan en los proverbios los recursos propios de la poesía, como es la búsqueda de la sonoridad (ritmo, juegos de palabras, aliteraciones), de la concisión y, en fin, amplio uso de imágenes y metáforas ${ }^{49}$. A estos les parece improbable que la sabiduría popular produzca tales joyas.

Pero en este caso y si la inscripción de Prov 25,1 es digna de crédito, que, a saber, los hombres de Ezequías recogieron los proverbios de la colección, habría que suponer que la escuela estaba en la corte real para la educación de los empleados. Ahora bien, la citada colección (25-29) de ninguna manera tiene un marcado carácter cortesano. Los Proverbios hablan de la vida como

48. G.VON RAD, La Sabiduría, 27-28; H.J. HERMISSON, Studien, 188; H. D PREUSS, Einführung in die alttestamentliche Weisheit. Stuttgart 1987, 37s. 143-150.

49. Véase L. ALONSO SCHÖKEL- J. VILCHEZ LINDEZ, Proverbios. Madrid 1984, 
la puede experimentar cualquiera. Una educación escolar en relación con la corte uno la esperaría de otra manera. Esto ya lo observó G. von RAD ${ }^{50} \mathrm{y}$ por ello creyó que debió haber escuelas o centros de cultura fuera de la capital.

Lo asomboso sería entonces que los hombres de Ezequías recogieran la sabiduría de estos centros de cultura populares y descuidaran la de la corte real, ellos precisamente que se supone vivían en la corte.

¿No será preferible suponer que los Proverbios provienen en gran parte de la sabiduría popular? Esta es la tesis de C. Westerman, de C. R. Fontaine, de F. Golka y otros ${ }^{51}$.

En efecto, ha sido fatal para la hipótesis escolar, el descubrimiento de la sabiduría popular de los pueblos iletrados, particularmente de Africa. Se ha observado en estos pueblos una sabiduría muy semejante a la bíblica. La forma es también gnómica, concisa y artística, expresada en proverbios. En cuanto al contenido se sorprenden los mismos temas: crítica del mentiroso y del perezoso, esmero en las relaciones con los demás, condena severa del mal, bajo cualquier forma que se presente, reconocimiento de Dios no sólo como creador sino también como protector del pobre y garante del orden moral. Tal es el parecido que L. Nare no teme afirmar que "la sabiduría bíblica parece construirse sobre el terreno de la sabiduría humana común" 52 .

Como es sabido las constataciones y consejos en el libro de los Proverbios están presentados como pronunciados por el padre y dirigidos a su hijo. Como esto sucede asimismo en Egipto y allí expresa la relación de maestro y discípulo, se da por seguro que en el libro de los Proverbios ocurre lo mismo. Pero a esto cabe responder que este lenguaje supone ciertamente que los padres instruían a sus hijos en sus casas; de lo contrario, este lenguaje sería inimaginable. Hay, además, textos como 1,$8 ; 4,3 ; 6,20 ; 10,1 ; 15,20$ en los cuales "padre" debe entenderse en sentido propio, puesto que se menciona a la madre. Y en todo caso si alguien quiere entenderlo como dichos del maestro a sus alumnos, debe probar que el contenido de algunos proverbios sólo son inteligibles como pronunciados en la escuela ${ }^{53}$. Las razones de esta afirma-

50. La Sabduría, 33.

51. C. Westermann ha insistido muchas veces sobre este punto. Véase su último libro donde da abundante bibliografía, Wurzeln der Weisheit. Die ältesten Sprüche Israels und anderer Völker. Göttingen 1990; C. R. FONTAINE, Traditional Sayings in the Old Testament. 1982; F. GOLKA, "Die Königs- und Hofsprüche und der Ursprung der israelitischen Weisheit": Vetus Testamentum 36(1986)13-36; ID. The Leopard's Spots. Biblical and African Wisdom in Proverbs. Edinburgh, 1994. -

52. L. NARE, Proverbes Salomoniens et Proverbes Mossi. Frankfurt-Bern-New York 1986 citado por C. WESTERMANN, Wurzeln, 177.

53. H. DELKURT, Ethische Einsichten in der alttestamentlichen Spruchweisheit. Neukirchen 1993,23-24. De la misma opinión es J. L. CRENSHAW, "Education in ancient Israel": JBL 104(1985) 614. 
ción son sencillas. Si se estudia temáticamente el libro, reuniendo los proverbios que tratan sobre las relaciones entre padres e hijos, hombre y mujer, o las contraposiciones entre el diligente y el perezoso o entre ricos y pobres, como lo ha hecho Delkurt, o las máximas que versan sobre el iracundo y el precipitado, o sobre el comercio, o bien sobre la administración de la justicia etc., nada se advierte en ellas que no se haya podido decir en la familia. En cambio, no se dice nada de las relaciones entre los alumnos, o del silencio que deben guardar, ni hay recomendaciones a escribir, etc. Estos temas sí serían característicos de la enseñanza escolar. Si a ello unimos la ausencia de contenidos políticos, como guerras, batallas, ciudades arruinadas etc. parece difícil afirmar que estos proverbios provienen de maestros de escuelas que en teoría debían preparar empleados para el gobierno.

4.2. En cuanto a Prov 1-9, B. Lang ha propuesto una interpretación original. Por supuesto coloca el "Sitz im Leben" en la escuela. No le ofrece dificultad alguna el hecho de que se mencione a la madre, pues entiende que esa mención viene exigida por el paralelismo de los miembros. Explicación ésta que no convence, puesto que muchas veces se menciona sólo al padre, y no por ello el paralelismo se quebranta. Cree que el mejor nombre que convendría darle a estos capítulos es el de libro escolar o antología literaria. Hoy tiene el papel de servir de introducción al resto de libro, pero antes era una pieza independiente, no necesariamente tardía; una especie de compilación de piezas para ejercicios de lectura o de escritura. Lo deduce del carácter de la colección que se compone de piezas disparatadas sin orden ni coherencia; no hay interés alguno en ir de lo más fácil a lo más difícil.

Apoya esta suposición en textos egipcios. Durante el imperio nuevo son numerosos los textos que los maestros han sacado de la memoria o de antologías precedentes en las que no hay gran profundidad de pensamiento ni coherencia, precisamente porque su finalidad era servir de libro de ejercicios para el dictado o la lectura. Tendríamos aquí, según él, un texto escolar en el A.T ${ }^{54}$.

Es posible que también en este caso la excesiva fijación en la sabiduría egipcia lleve a resultados fallidos.

R. N. Whibray, que ha dedicado mucha atención a los libros sapienciales, fue el primero que individuó en Prov 1-9 diez instrucciones que un padre dirige a su hijo. Ellas constituyen el núcleo original de estos capítulos. En su forma primitiva eran breves, pero sufrieron adiciones sapienciales y yahvistas. Hoy comprenden los siguientes trozos: 1, 8-19; 2, 1-22;; 3,1-12. 21-35; 4,19.10-19.20-27; 5; 6,20-35; 7 55. Además, estos capítulos contienen tres poemas

54. B. LANG, "Schule und Unterricht", 193-196. Cita aquí sus dos obras anteriores donde ha expuesto las mismas ideas.

55. The Concept of Wisdom in Proverbs I-IX. Oxford, 1992. 
en los que la sabiduría habla en primera persona (la sabiduría personificada: 1,20-33; 3, 13-20; 8, 1-36).

En un reciente libro estudia la composición del libro de los Proverbios. Sus puntos de vista resultan interesantes para el tema que tocamos ${ }^{56}$.

El esquema y la fraseología de las instrucciones son muy parecidas: son exhortaciones de un padre a su hijo. Comienzan todas con el mandato de escuchar: "escucha, hijo...". Luego el padre prosigue enfatizando la importancia de la propia doctrina y finalmente se dan mandatos, casi siempre bastante concretos. Cuatro de las instrucciones $\left(2^{a}, 8^{a}, 9^{a}\right.$ y $\left.10^{a}\right)$ exhortan a evitar la tentación de la adúltera, lo que hace usando un lenguaje muy parecido. La primera advierte del peligro de andar con compañeros que practican la violencia y el asesinato. La tercera es la única que habla de las relaciones con Dios, que forma pareja con la siguiente que trata de las relaciones con los demás. La quinta es singular, pues el padre recuerda cómo él fue a su vez enseñado por su padre anteriormente. Y finalmente la sexta que trata del mismo tema que la primera.

Dado que el contenido de las instrucciones en su tenor original es concreto y advierte de peligros a que el joven de entonces y de ahora está expuesto (violencia, sexo y conducta impía), no hay ninguna razón para no entenderlas como exhortaciones de un padre a su hijo. Son ejemplos de un género literario. No formaron parte primitivamente de un libro, de lo contrario no se entiende por qué se recogen instrucciones tan parecidas formalmente y que tratan del mismo tema con casi idéntico vocabulario.

Por otra parte, los poemas de la sabiduría no pueden haber sido pronunciados por un maestro en la escuela, como piensa B. Lang. Por muy enfadado que estuviera el maestro por el comportamiento rebelde de los alumnos no se le puede atribuir la autoridad cuasi divina que se arroga la sabiduría (1, 20-33) amenazando con la muerte y la perdición al que no le haga caso.

Más vale reconocer con O. PLÖGER que "en el libro de los Proverbios no aparece ningún argumento que confirme la existencia de escuelas" 57.

\section{La arqueología y la epigrafía}

Descubrir e interpretar los restos de las civilizaciones pasadas es el papel de estas ciencias. Es natural, por tanto, que se haya buscado en ellas pruebas o indicios de la existencia de las escuelas. Sin embargo, es difícil en principio que la arqueología pueda aportar datos fehacientes acerca de nuestro tema. El arqueólogo descubre ruinas. Las escuelas de la antigüedad dejaban pocos restos de su existencia. Ni siquiera es fácil identificar el sitio de las escuelas

56. The Composition of the Book of Proverbs (JSOT.SS 168). Sheffield 1994.

57. Sprïche Salomos (Proverbia). Neukirchen 1984, XXI. 
en Mesopotamia y en Egipto, donde ciertamente existían. Menos aún será posible encontrar restos de los edificios escolares en Israel, dado que existieran. Hay que imaginarse que las escuelas egipcias o mesopotámicas serían una sala o un rincón en la plaza pública.

Por lo que se refiere a Palestina, solamente un local ha sido propuesto como sala escolar. A. Lemaire ${ }^{58}$ ha creido ver en una sala descubierta en Kuntilat Ajrud una escuela. Estas serían las razones: la sala está provista de un banco alrededor de las paredes, y las inscripciones, que interpreta como ejercicios escolares, están grabadas sobre pithoi o ánforas grandes, cuyas superficies podían haber sido usadas como encerado.

Sin embargo, es preciso tomar esta identificación con mucha reserva. Los arqueólogos que excavaron las ruinas creen que se trata de un centro de culto y la famosa sala no es más que el almacén donde se guardaban las ofrendas de los fieles ${ }^{59}$.

Por su parte la epigrafía, como su nombre indica, estudia las inscripciones antiguas. También en ellas se ha querido encontrar indicios favorables a la enseñanza escolar. Ha sido el citado A. Lemaire quien ha reunido las inscripciones descubiertas hasta 1981 que pudieran interpretarse como ejercicios escolares o textos didácticos. Concretamente se trata de inscripciones que pudieran ser abecedarios, es decir, lista de las letras que se han usado siempre en las escuelas para iniciar al alumno en el conocimiento de la lectura y de la escritura. En unos veinte lugares del antiguo Israel y regiones vecinas se han encontrado abecedarios de este tipo. No todos ellos son de igual valor, pues algunos sólo tienen un par de letras. Citaremos las más importantes, todos ellos anteriores al destierro.

Un ostrakon (XII-XI) de Izbet Sartah, junto a Afeq contiene 5 líneas. En la quinta línea puede leerse con mucha dificultad el alfabeto con las 22 letras. Hay que notar que no se trata de una escritura a tinta, sino de una incisión muy leve sobre un cascote de una vasija.

En Lakish se han encontrado tres abecedarios. Uno grabado en un peldaño de la escalera que da acceso a la fortaleza. En él se leen las cinco primeras letras. El segundo es un ostrakon escrito a tinta muy borrosa y en el que se puede leer con dificultad en la primera línea la secuencia alfabética desde la ghimel a la lamed, en la segunda línea, desde la mem a la resh y en la tercera, shin taw ${ }^{60}$. Por último en un almacén se encontraron restos de una jarra con las cuatro primeras letras del alfabeto grabadas.

58. Le scuole, 31-32.

59. Z. MESHEL, "Kuntilat Ajrud. A Holy Site from the Period of the Monarchy on the Sinai Border": Qadmoniot 9(1977) 119-124.

60. E. PUECH, "Les Ecoles dans l'Israël préexilique: données epigraphiques": Congress Volume. Jerusalem 1986, J. A. Emerton (edit). Leiden 1988, 190 reproduce el facsímil del ostrakon. 
En Khirbet el-Qom en la pared rocosa de una tumba se han encontrado grabadas las dos primeras letras del alfabeto, y quizá encima el alef y el ayin.

Por su parte en Aroer (Negeb) en un pequeño ostrakon se puede leer $q r$.

En las excavaciones de Qadesh-Barnea se encontró un ostrakon en el que se hallan escritas estas tres letras: zayin, het, teth.

Finalmente en Kuntilet Ajrud en uno de los pithoi o ánforas grandes se hallaron tres fragmentos de abecedarios, uno encima de otro, escritos por diferentes personas. Ninguno está completo, pero todos ellos tienen varias letras seguidas en el orden usual.

En otra ánfora se ha encontrado la famosa bendición que tanta tinta ha hecho correr. Dice así: Te bendigo por Yahve de Samaria y por su Ashera. Como no sigue ningún mensaje, A. Lemaire piensa que es ejercicio escolar.

A veces se cita la piedra calcárea de Gezer pero es un calendario agrícola de 12 meses y nada permite atribuirle un origen escolar.

De estos abecedarios tan incompletos la mayor parte de ellos, así como de otras brevísimas inscripciones, que, por estar las letras mal dibujadas se piensa que pertenecen a un principiante, deduce A. Lemaire la existencia de una escuela en el lugar donde se han encontrado ${ }^{61}$.

Contra esta conclusión se han levantado críticas que imponen más prudencia ${ }^{62}$.

Prescindiendo de la observación evidente de que una golondrina no hace primavera, tanto el lugar donde se han encontrado como el material de las inscripciones, hablan en contra de la conclusión referida.

Es disparatado pensar que el supuesto abcedario de Khirbet el-Qom (y decimos supuesto, porque se reduce a dos letras), sea testigo de la existencia de una escuela. El lugar, una tumba, no es ciertamente apropiado para tal institución. El abecedario de Izbet Sartah difícilmente puede ser entendido como testigo de una escuela. La ciudad más próxima, Afeq, está a $3 \mathrm{~km}$. Es improbable que los chicos tuvieran que hacer este kilometraje diariamente.

De Aroer cabe decir que el poblado era tan pequeño que no es probable que hubiera allí escuela. Además el ostrakon sólo contiene dos letras, y por tanto es muy dudoso que sea un abecedario. M. Haran hace una observación atinada. En Nahal Michmash se encontró un abecederario de la época postexílica. Ahora bien, el lugar solamente es accesible con una escalera de cuerda.

Tampoco el material en el que están escritos los abecedarios permiten pensar en la enseñanza escolar. Se hace difícil creer que el abecedario grabado en el peldaño de la escalera de Lakish forme parte de la enseñanza escolar. Ni el lugar ni el modo de escribir es propio de la escuela. No se puede

61. A. LEMAIRE, Le Scuole, 11-33.

62. M. HARAN, "On the Diffusion of Literacy and Schools in Ancient Israel": J. A. EMERTON (ed.), Congress Volume. Jerusalem 1986. Leiden, 1988, 81-95; E. PUECH, "Les Ecoles", 189-203. 
pensar que el alumno en clase, para escribir, tuviera que grabar. Lo normal era que se usara tinta. Tampoco es imaginable que los alumnos usaran esos grandes pithoi o ánforas de Kuntilet Ajrud para escribir. En la Biblia se citan varias veces como material de escritura las tablillas de madera (Isa 30,8; Hab 2,22). Estas eran usadas también en Egipto, al mismo tiempo que ostraka y tinta. Y esto mismo debió hacerse en Israel. Al fin y al cabo era el material más barato. Por tanto, los abecedarios grabados en piedra o en cascotes de vasijas de arcilla o escritos en paredes enyesadas no sirven como indicadores de actividad escolar. Su existencia puede explicarse de otra manera. Pueden tener un significado mágico-religioso ${ }^{63}$ o también como ensayos de un alfarero o grabador. El que estén escritos de manera deficiente caligráficamente (ésta es la razón para atribuirlos a un escolar), puede también entenderse como ejercicio de un alfarero que estaría en las mismas circunstancias que un joven alumno.

El único abecedario que pudiera ser obra de un escolar es el abecedario de Lakish.

\section{La arqueología sociológica}

Ya desde hace años se viene aplicando la sociología a la reconstrucción del pasado de Israel. Piénsese, por ejemplo, en las discusiones existentes sobre el origen de Israel, o sobre el tránsito israelita de una sociedad acéfala a un estado monárquico. La sociología en estos casos proporciona el análisis de variables, factores sociales y económicos que permiten una mayor comprensión de la sociedad antigua.

También la sociología puede ser aplicada a los datos obtenidos por la arqueología. En este caso, el resto material recuperado por la arqueología no se apreciará tanto por su carácter singular, sino conjuntamente con otros datos o variables, en definitiva, con otros indicadores, que permitan abrir un amplio abanico de posibilidades de explicación del dato y establecer criterios para escoger entre ellas. Un resto arqueológico es la conversión de una parte de la energía de una sociedad en algo material. Aplicando esto a la enseñanza escolar, quiere decir que si una sociedad es capaz de dedicar individuos a esta labor, sólo será posible si la economía lo permite. Un análisis de la economía de la región, o de la existencia de otros gastos suntuarios o de lujo, permitirá aportar más información sobre la posibilidad de las escuelas.

Esta incorporación de la sociología a la arqueología con el fin de analizar la existencia de la enseñanza escolar en el antiguo Israel ha sido hecha por D. W. Jamieson-Drake ${ }^{64}$, que aporta datos interesantes que merecen ser tenidos en cuenta.

63. M. HARAN, "On the diffusion", 93-94. 
La capacidad de escribir, la existencia de unos maestros que tienen esta técnica no es un dato que deba ser considerado aislado, presupone y va unido a otros indicadores fuertemente relacionados, pues el escriba no es un vulgar escribano, sino una pieza importante en el control adminitrativo y en la organización de la sociedad. Indicadores muy importantes relacionados con el escriba son éstos: control administrativo centralizado, es decir, concentración de funciones en muy pocos lugares, estratificación social (o diversidad de clases sociales) y la existencia de otros especialistas dedicados a una actividad no directamente agrícola. Estas características no son directamente observábles, pero se pueden colegir de los restos materiales directamente relacionados con ellas. Estas tres variables o indicadores escoge JamiesonDrake siguiendo a otros autores (p. 37-47): 1) el estudio de los asentamientos, su distribución, su mayor o menor densidad de población; 2) las obras públicas y 3 ) los objetos de lujo.

$\mathrm{El}$ análisis se basa en las excavaciones publicadas y en las observaciones de superficie y se limita al territorio de Judá mas o menos.

En cuanto al primer punto afirma Jamieson-Drake que Ios s. XII y XI pueden ser considerados como un periodo de estabilidad; pocos cambios se dieron. A partir del s. x comienza una fuerte concentración de la población en menos y mayores asentamientos. Fue obligatorio explotar más y mejor los recursos. A partir del s. IX y sobre todo en el s.VIII Jerusalén se convirtió en el núcleo urbano por excelencia, concentrando las funciones administrativas y económicas. También debió crecer entonces la estratificación social.

De estas observaciones concluye con referencia a los escribas que durante los s. XII y XI no hay constatación alguna de un aumento de los controles administrativos. La falta de cambios drásticos sobre un periodo relativamente largo sugiere pocas alteraciones en la producción agrícola o en la defensa frente a otras fuerzas interiores o exteriores. Dada esta débil estructura administrativa, no hay razón alguna para colocar en estos siglos una institución como los escribas.

Con sorpresa observa que tampoco el periodo siguiente (s. X) ofrece cambios significativos en los sistemas del control administrativo. Por el contrario, el cambio más importante es la concentración de la población, que se debió a otras fuerzas no precisamente administrativas. La fragmentación que experimentó el estado a la muerte de Salomon prueba que la administración davídica no era un sistema consolidado. No existió, pues, necesidad alguna para crear un cuerpo de escribas profesionales o administradores hasta el s. IX.

Las obras públicas son un magnífico indicador de los sistemas de control administrativo. Reflejan una concentración de trabajo y recursos naturales

64. Scribes and Schools in Monarchic Judah. A Socio-Archeological Approach. (JSOT. SS. 109). Sheffield, 1991. 
conforme a diversas variables: no sólo el tamaño, sino también su función, modo de construcción, y calidad de la obra.

Tres restos arqueológicos son candidatos para su clasificación como obras públicas: murallas, edificios, sistemas de traida de aguas.

Durante el s. X, la actividad inversora se concentra en la zona montañosa, preferentemente en torno a Jerusalén.

En el s. VIII se observa un gran incremento (ca. 300\%) en la edificación de murallas, instalaciones de agua y fortalezas. Los proyectos son planificados de una manera centralizada y menos dispersa, concentrándose en Jerusalén y Lakish.

En el s. VII la edificación de muralllas baja drásticamente (400\%), mientras que la construcción de edificios públicos permanece igual. En el s. VI no hay proyecto alguno nuevo de edificios.

Las obras en murallas e instalaciones de agua crecen mucho en los s. X y VIII. En ambos casos es respuesta a presiones exteriores: de los filisteos y Egipto en el primer caso; en el segundo, de Asiria. Pero la respuesta es muy distinta: en el s. viII, la capacidad para habilitar recursos es mucho mayor que en el s. X. La diferencia está en la cantidad, dificultad y envergadura de las obras.

Cabe, pues, hablar de control administrativo ya en el s. $\mathrm{x}$, debido a la duplicación de los planes de edificios en sitios dispersos. Sin embargo el grado de control administrativo requerido es bajo. Cambia el panorama cuando llegamos al s. viII. La diferencia entre el trabajo empleado en los dos mayores sitios (Jerusalén y Lakish) y el resto de los lugares ha crecido del 40 al $500 \%$. La evidencia de una administración centralizada, capaz de proyectar trabajo y material, aparece por vez primera en este siglo con la construcción de dos grupos de tres fortalezas en la parte sur de Judá.

La conclusión parece evidente: los incrementos en cantidad y calidad de las obras públicas en el s. VIII prueban la evidente necesidad de un sistema de control administrativo y por lo mismo la necesidad de escribas desde esa época.

Por artículos de lujo se entienden aquellos objetos cuya adquisición es limitada: joyas y objetos de cosmética, metales, utensilios de cerámica, incripciones, sellos, etc.

Se nota un fuerte incremento de objetos de lujo en el paso de los siglos XII y XI al s. X. La conclusión es que la economía regional fue mucho más productiva en este siglo que en los dos anteriores.

Pero cuando más se nota el incremento es en el s. viIl y alcanza su zénit en el s. VII. La explicación mas probable es una mayor producción de bienes no agrícolas. Hay objetos de fabricación extranjera, pero no se constata la existencia de un comercio sistemático y continuado con el exterior. En cambio, hay pruebas bastante claras de la regulación centralizada de la distribución de bienes agrícolas a partir del s. VIII. Las jarras impresas con un escara- 
bajo y con la inscripción Lammelek = "del Rey" es buena prueba de ello. La misma conclusión cabe extraer de la existencia de pesas estandarizadas que aparecen a partir del s. viII. Por tanto, también aquí los indicios de una administración centralizada sólo comienzan a aparecer a partir del s. VIII.

Quizá ésta sea la conclusión que más pueda extrañar. Pero, no hay evidencia alguna de que Judá haya funcionado como estado hasta el s. viII. Sólo en este tiempo Judá, por el incremento de la población, cantidad de edificios públicos, producción de bienes, centralización y especialización necesitó de un cuerpo de administrativos a cierta escala.

Jamieson-Drake no está sólo en esta afirmación. La total ausencia de datos epigráficos desde el s. XII al s. IX ha extrañado tanto a G. Garbini, que le ha llevado a negar la supuesta grandeza del reinado de David y Salomón 65.

\section{Conclusión}

Se han buscado argumentos a favor de las escuelas desde múltiples diciplinas. El mismo hecho de recurrir a tantas instancias demuestra que la existencia de esta institución no es nada clara.

Las instituciones de una sociedad deben estudiarse desde un punto de vista funcional. No deben suponerse sin más. La existencia de ellas dependen del grado desarrollo de la sociedad. Israel hasta el s. vIII no alcanza una escala en la que aparezcan indicadores de la necesidad de una administración bastante numerosa.

Hemos visto cómo los ostraka comienzan a aparecer en el s. viII. No hay ninguna razón para que no aparecieran de otras épocas anteriores si la escritura hubiera existido a gran escala.

Correspondería con los hallazgos de la arqueología la noticia de Prov. 25, 1 que habla de "los sabios, hombres de Ezequías que escriben los proverbios". Es, pues, probable que en el tiempo de Ezequías por necesidades sociales comenzaran a prepararse algunos escribas ${ }^{66}$. Es prácticamente seguro que esta formación se hizo en Jerusalén en una sola escuela. E. Puech ${ }^{67}$ se inclina a pensar que no debieron ser muchos lo que sabían escribir. Observa en los ostraka una grafía conservadora, ortografía fija y bien impresa, con ya ciertas reglas como la diptongación y asimilación de unas letras con otras, etc. Si la escritura hubiese sido más general la ortografía sería más fluctuante.

65. G. GARBINI, "Dati epigrafici e linguistici sul territorio palestinese fino al VI secolo a.C": Rivista Biblica 32(1984) 67-83.

66. J .L. CRENSHAW, Education, 614.

67. Les ecoles, 201-202. 
Lo dicho anteriormente vale únicamente para la(s) escuela(s) de escribas. La escuela dirigida a cubrir las necesidades básicas de leer y escribir de la población en generaı no pueden suponerse hasta una época muy tardia, ciertamente posterior a la época persa.

Constantino Mielgo.

Estudio Agustiniano

Valladolid 